\title{
Institutions in transitioning peri-urban communities: spatial differences in groundwater access
}

\author{
Sharlene L. Gomes and Leon M. Hermans \\ Department of Technology, Policy, and Management, Delft University of Technology, \\ Delft, 2628BX, the Netherlands \\ Correspondence to: Sharlene L. Gomes (s.l.gomes@tudelft.nl) \\ Published: 12 May 2016
}

\begin{abstract}
Urbanization creates challenges for water management in an evolving socio-economic context. This is particularly relevant in transitioning peri-urban areas like Khulna, Bangladesh where competing demands have put pressure on local groundwater resources. Users are unable to sufficiently meet their needs through existing institutions. These institutions provide the rules for service provision and act as guidelines for actors to resolve their water related issues. However, the evolving peri-urban context can produce fragmented institutional arrangements. For example in Khulna, water supply is based on urban and rural boundaries that has created water access issues for peri-urban communities. This has motivated local actors to manage their groundwater needs in various ways. General institutional theories are well developed in literature, yet little is known about institutions in transitioning peri-urban areas. Institutions that fail to adapt to changing dynamics run the risk of becoming obsolete or counter-productive, hence the need for investigating institutional change mechanisms in this context. This paper examines peri-urban case studies from Khulna using the Institutional Analysis and Development framework to demonstrate how institutions have contributed to spatial differences in groundwater access with local actors investing in formal and informal institutional change as a means of accessing groundwater.
\end{abstract}

\section{Introduction}

The global south is expected to witness significant levels of urbanization in the coming decades which will have implications for the management of water resources (UN DESA, 2014). We see evidence of this in the Ganges Delta, where rapid and largely uncontrolled urban expansion has brought growing concerns of water scarcity, competition, and inequity among users (Kumar et al., 2011; Thissen et al., 2013). The situation is particularly severe in peri-urban areas surrounding Khulna city, Bangladesh, where groundwater is the main source for domestic and livelihood purposes.

Peri-urban areas are dynamic, representing the transition zones in processes of urban expansion with a heterogeneous composition (Allen, 2003; Narain, 2010). In such a context, the management of groundwater resources requires a coordinated approach among actors, based on a shared set of rules. Institutions are defined as formal and informal "rules" that structure interaction and behavior in society (North, 1990). They offer a means for resolving social dilemmas by offer- ing prescriptive guidelines. However, peri-urban villages in Khulna have witnessed the failure of existing institutions in managing water resources in a sustainable and equitable way (Thissen et al., 2013). Achieving effective institutional arrangements in this context, however, is complex. Institutions are expected to evolve with the changing context, yet this is not always possible due to various actor constraints that prevents this. This can result in the creation of a fragmented mix of rural and urban institutions. This research explores how peri-urban institutions and institutional change has contributed to spatial differences in groundwater access in periurban Khulna.

\section{Conceptual framework for peri-urban institutional analysis}

The adapted Institutional Analysis and Development (IAD) framework in Fig. 1 focuses on key aspects relevant to the study of institutions and institutional change. The analysis 




Figure 1. IAD Framework (adapted from Ostrom, 2005).

centres around the action arena, consisting of interactions between multiple actors with an ability to influence their system of interest. In this case, the action arena refers to periurban groundwater management. Strategic behaviour within this arena and its resulting outcome is based on contextual variables such as the institutions or "rules in use", community attributes such as socio-economic conditions, and biophysical conditions (Ostrom, 2005)

The institutional context includes consciously designed and codified formal laws, constitutions, or property rights as well as informal, socially constructed norms and values that together comprise a society's culture (North, 1990; Williamson, 1998). They define the participants, their position, resources, possible actions, and the costs and benefits of their associated outcomes within the action arena (Ostrom, 2005). In society, these institutions are organized in a nested structure from local operational rules to increasingly embedded higher order collective choice, constitutional, and metaconstitutional rules (North, 1990; Ostrom, 2005; Williamson, 2000).

Feedback loops from the outcomes are an important part of this framework offering a means to study institutional change. North (1996) describes institutional change to arise through a process of actor learning from the outcomes of their strategic decisions. Here, negative outcomes are a signal to change strategies or alter the institutions in order to achieve their objective. Although institutions are expected to evolve with actor's needs in this manner, this is not always the case. Theories highlight that the embeddedness of rules brings a higher transaction costs for actors investing in institutional change (North, 1990). As a result, institutions may gradually become eroded over time, replaced, or ignored altogether without purposive action (Scharpf, 1997). Moreover, institutions are not socially efficient, so institutional change also depends on the bargaining power of the actors involved (North, 1990, 1996). In Fig. 1, system feedback resulting in observed changes to the biophysical and socio-economic context is differentiated from actor feedback that produces institutional change, given this is a key research objective.

\section{Methodology}

Institutional aspects of groundwater access in peri-urban Khulna is analyzed using the framework in Fig. 1. The villages of Hoglandanga and Matumdanga are selected as case studies given the peri-urban characteristics they display and evidence of groundwater issues. They are currently witnessing urban expansion and are formally located outside Khulna city jurisdiction. Multi-actor interactions in groundwater access, an issue highlighted by both communities, is examined within the contextual variables. Field research reveals three key stages in the evolution of this issue representing the past, present, and future scenario of ground water access. In each stage, the study examines the form of institutional change invested in to manage groundwater access.

Primary data from government websites and published reports is verified and supplemented through field discussions with 18 respondents from government agencies and water users in both villages (Gomes, 2015). Interviewees were selected through structured and snowball sampling methods (Harrell and Bradley, 2009). Interview methods include focus group discussions and key informant interviews. Field data gathered in May-June (2015) was subsequently verified through a de-briefing meeting with local actors or email communication. Formal and informal institutions are analyzed based on their level of operation in the nested structure and the action arena variables they define (Ostrom, 2005). 


\section{Results}

\subsection{Initial situation: rural service provision}

Both peri-urban villages fall under the jurisdiction of rural service providers such as the Department of Public Health Engineering (DPHE) and the Bangladesh Agricultural Development Corporation (BADC) for domestic and irrigation purposes respectively. Tube wells are provided via water and sanitation (WATSAN) or Irrigation committees at the subdistrict level, headed by the sub-district chairman with representatives from local unions, BADC, and DPHE (BADC, 1985; Local Government Division, 1998). Villages may apply for a tube-well licence through written application at their local union after which the committee decides the allocation of licences among the villages. Allocation is based on the following selection criteria: aquifer conditions, distance from neighbouring tube wells, beneficial area, effect on existing tube wells, and suitability of sites as per formal rules (BADC, 1985; Gomes, 2015). However, this quota system does not appear to be fully operational in practice with insufficient tube wells provided in the past 4-5 years (Gomes, 2015). Public tube wells from DPHE are provided at a subsidized cost, making this an attractive option for those unable to invest in a private tube well. The resulting outcome is that of water scarcity due to the failure of formal institutions. Community discussions give the impression that their remote location away from the administrative centre limits their voice in the sub-district committee (Gomes, 2015)

\subsection{Current situation: informal service provision}

Given this outcome, the villages adopted a new strategy by creating informal institutions to access groundwater. Presently, local private tube well owners sell groundwater to marginalized irrigators. Tariffs are agreed upon by both parties, although it is unclear if there are negotiations or if the prices are elastic given the seasonal scarcity highlighted in both communities. In Matumdanga, water from shallow aquifers was sold in 2015 at a rate of 33-45 EUR $0.5 \mathrm{ha}^{-1}$ per season for unlimited use while in Hoglandanga the shrimp farmers pay a rate of approximately $0.5 \mathrm{EUR} \mathrm{h}^{-1}$ to cover fuel and electricity costs (Gomes, 2015). Meanwhile, domestic users have informal rules for sharing existing tube wells such as a first come first serve and queue system to collect water. Women in Matumdanga, typically responsible for household water collection follow rules in the Muslim culture by avoiding water collection from their local Mosque during hours of prayer (Gomes, 2015).

\subsection{Future situation: urban service provision}

A potential future scenario of institutional change results as a by-product of urbanization. Khulna Water Supply and Sewerage Authority (KWASA) caters to the water and sanitation needs of Khulna city. Currently, $95 \%$ of the water supply is from groundwater resources via private and shared tubewells, however, KWASA plans to extend coverage through surface water projects funded by donor agencies (Gomes, 2015). Urban administration is managed by the Khulna City Corporation (KCC) who in 2007 and 2014 submitted proposals to extend city boundaries from 45 to $114 \mathrm{~km}^{2}$ based on the Khulna master plan (Gomes, 2015). Once approved, the plan would bring Matumdanga and Hogladanga villages under KCC jurisdiction, making water supply the responsibility of KWASA. However, KWASA currently faces a supply gap, with unserved areas presently relying on private tube wells (Gomes, 2015). Thus, it is unclear if groundwater access could improve in these villages under urban administration in the future.

\section{Discussion}

These results show how peri-urban water access in Khulna is influenced by institutions. Formal institutions in the initial stage produced spatial differences in groundwater access between areas with and without tube well allocations. Although policies specify rules for allocation, lack of adequate enforcing and monitoring mechanisms can be a deterrent to its functioning at the local level. Monitoring and enforcement of rules can help prevent opportunistic behavior by placing a higher risk for those considering defecting (Ostrom, 2005). The need for enforcement, however, depends on whether there is a known willingness for local committees to deviate from rules. There appear to be potential payoffs for some elected members within the committee to support deviation. One could be internal reciprocal norms to appease the constituencies that elect them, which influences their decision. Or it may be the result of conflicting rules such as the Bangladesh Water Act (2013) promoting the right to water and others stating that communities should play a greater role in managing the costs for water services (Local Government Division, 1998; Ministry of Law, Justice and Parlimentary Affairs, 2013; Ministry of Water Resources, 1999). Greif (2006)'s theory on legal pluralism highlights that rules may be complementing, reinforcing, or conflicting to one another. Furthermore, limited understanding of the context in the design of rules or combination of rules can produce unintended or disastrous outcomes (Ostrom, 2005). Thus, research needs to look beyond local allocation rules to higher order rules or rules from other sectors and how they work in relation to one another.

The undesirable allocation outcome prompted local actors to invest in institutional change in order to meet their water needs. In the current situation, we observe that institutional change depends on one's resources. The location of both villages away from rural decision centers, give users limited bargaining power to seek a more equitable distribution of licenses. Thus, actors chose to invest in informal institutional change given the high transaction costs. Here, we see differ- 
ent sets of informal rules for irrigators and domestic users. While irrigators opted for a market system to access groundwater, domestic users share existing tube wells. The latter bears less financial implications but has costs in terms of time, distance travelled, and convenience. Thus, even with informal institutions we see differences in the options between peri-urban users.

In the future, constitutional level rules could again influence groundwater access through urbanization. Formal change by replacing rural with urban service provision creates some uncertainties for users in these communities. For domestic users there is the risk that existing gaps in urban water supply will continue, once again creating spatial difference in access within urban areas. For irrigators, future groundwater dependency is uncertain given the existing changes in land use (Gomes, 2015). When peri-urban villages come under KCC jurisdiction, the fate of peri-urban land will depend upon the master plans. So it is likely that land use will be a bigger uncertainty than water access.

\section{Conclusion}

Problems in peri-urban Khulna show that institutions fail to effectively manage groundwater access during urban transitions. It also highlights the challenges with institutional design in this context. The changing needs in peri-urban areas mean existing institutions across a rural-urban divide become ineffective over time causing spatial patterns in water access. Addressing inefficient rules needs to consider how they are applied in practice. Understanding actor motivations and objectives can help in this regard. In Khulna, we observe a shift from formal to informal institutions with the future bringing yet another formal change. Theories suggest that institutions work if they are stable in the long term but this is not possible given the dynamics of peri-urban areas. Thus peri-urban areas are challenged with balancing functionality with stability, the former addressed in this case through informal means. This research signals that improving water management during urban transitions requires focusing on the institutional context, for which the IAD framework offers a means to operationalize key concepts in the peri-urban context.

Acknowledgements. This research was funded by the Urbanising Deltas of the World programme of the Netherlands Organisation for Scientific Research (grant no. W 07.69.104), "Shifting Grounds: Institutional transformation, enhancing knowledge and capacity to manage groundwater security in peri-urban Ganges Delta systems". Thanks are due to Wil Thissen and Vishal Narain for their critical reflections on the ideas presented. Also to A. T. M. Zakir Hossain, Sk. Nazmul Huda, and Md. Riad Hossain from Jagrata Juba Shangha and Md. Rezaul Hasan from Bangladesh University of Engineering and Technology for valued assistance during the fieldwork in Bangladesh.

\section{References}

Allen, A.: Environmental planning and management of the periurban interface: perspectives on an emerging field, Environ. Urban., 15, 135-148, doi:10.1177/095624780301500103, 2003.

BADC: The Groundwater Management Ordinance, available at: http://bdlaws.minlaw.gov.bd/pdf_part.php?id=686 (last access: 31 January 2016), 1985.

Gomes, S. L.: Pre-scoping Visit-Field Report, Khulna, Delft University of Technology, Delft, the Netherlands, 2015.

Greif, A.: Institutional Trajectories: How Past Institutions Affect Current Ones, in: Institutions and the Path to the Modern Economy: Lessons from Medieval Trade, Cambridge University Press, New York, USA, 2006.

Harrell, M. C. and Bradley, M. A.: Data Collection Methods: SemiStructured Interviews and Focus Groups, RAND Corporation, Santa Monica, California, USA, 2009.

Kumar, U., Khan, M. S. A., Rahman, R., Mondal, M. S., and Huq, H.: Water Security in Peri-Urban Khulna: Adapting to Climate Change and Urbanization, Discussion Paper No. 2, SACI WaterS, Secunderabad, Andhra Pradesh, India, 2011.

Local Government Division: National Policy for Safe Water Supply and Sanitation, available at: http://www.dphe.gov.bd/pdf/ National-Policy-for-Safe-Water-Supply-\&-Sanitation-1998.pdf (last access: 31 January 2016), 1998.

Ministry of Law, Justice and Parlimentary Affairs: Bangladesh Water Act, available at: http://www.ielrc.org/content/e1313.pdf (last access: 31 January 2016), 2013.

Ministry of Water Resources: National Water Policy, available at: http://www.buet.ac.bd/itn/publications/sector-documents/ documents/National_Water_Policy.pdf (last access: 31 January 2016), 1999.

Narain, V.: Periurban water security in a context of urbanization and climate change: A review of concepts and relationships, SaciWATERS, available at: http://saciwaters. org/periurban/idrcperiurbanreport.pdf (last access: 22 October 2014), 2010.

North, D. C.: Institutions, Institutional Change and Economic Performance, Cambridge University Press, Cambridge, UK, 1990.

North, D. C.: Epilogue: Economic Performance Through Time, in: Emperican Studies in Institutional Change, Cambridge University Press, Cambridge, USA, 342-355, 1996.

Ostrom, E.: Understanding Institutional Diversity, Princeton University Press, Princeton, NJ, USA, 2005.

Scharpf, F. W.: Games Real Actors Play: Actor- Centered Institutionalism in Policy Research, Westview Press, Boulder Colorado, USA, 1997.

Thissen, W. A. H., Hermans, L. M., Prakash, A., Banerjee, P., Khan, M. S. A., Salehin, M., Narain, V., Kempers, R., Hossain, A. T. M. Z. P., and Banerjee, P. S.: Shifting Grounds: Institutional transformation, enhancing knowledge and capacity to manage groundwater security in peri-urban Ganges Delta systems, Project Proposal for the Urbanizing Deltas of the World programme of the Netherlands Organization for Scientific Research, Delft University of Technology, Delft, the Netherlands, 2013.

UN DESA: World Urbanization Prospects: The 2014 Revision, Highlights, No. ST/ESA/SER.A/352, United Nations, New York, USA, 2014. 
Williamson, O. E.: Transaction cost economics: how it works; where it is headed, De Economist, 146, 23-58, 1998.
Williamson, O. E.: The new institutional economics: taking stock, looking ahead, J. Econ. Lit., 38, 595-613, 2000. 